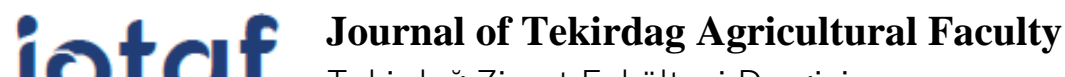 \\ Tekirdağ Ziraat Fakültesi Dergisi
}

Eylül/September 2019, 16(3)

Başvuru/Received: 27/08/19

Kabul/Accepted: 08/09/19

DOI: 10.33462 jotaf.570617

http://dergipark.gov.tr/jotaf

http://jotaf.nku.edu.tr/

ARAŞTIRMA MAKALESİ

RESEARCH ARTICLE

\section{Başlangıç Yemine İlave Edilen Mısırın Siyah Alaca Buzağılarda Yem Tüketimi ve Büyüme Performansı Üzerine Etkisi}

\author{
Effects of Whole Corn Grain Supplementation on Intake and Growth in Holstein Calves
}

\author{
Ekin SUCU* Emrah GÜLGÜN ${ }^{1}$ Ahmet OKUMUŞ ${ }^{1}$
}

\begin{abstract}
Öz
Bu çalışma, buzağı başlangıç yemine ilave verilen bütün mısırın buzağılarda yem tüketimi ve büyüme performansı (doğumdan 63. gün yaşa kadar) üzerindeki etkilerinin incelenmesi amacıyla yürütülmüsşür. Buzağılar bireysel bölmelere alınmadan önce tartılmış̧ır. Buzağılar, başlangıç canlı ağılıkları ve cinsiyetleri dikkate alınarak rasgele 2 gruba ayrılmıştır. Buzağılar ilk 3 gün kolostrum, 3 . günden itibaren ise süt ikame yemi ile beslenmişlerdir. Birinci grup hayvanlar süt ikame yemine ek olarak buzağı başlangıç yemi (Kontrol grubu) ile beslenmişlerdir (10 dişi ve 10 erkek). İkinci grup buzağılar ise süt ikame yemine ek olarak buzağı başlangıç yemi ve bütün mısır ile beslenmişlerdir (10 dişi ve 9 erkek). Katı yemler ve su buzağılara sınırsız olarak sağlanmıştır. Deneme boyunca, buzağıların doğum boyları ve doğum ağırlıkları ile canlı ağırlık artışları üzerinde; cinsiyet, muamele ve muamele $\times$ cinsiyet interaksiyonunun etkileri önemsiz bulunmuștur $(P>0.05)$. Misır ile beslenen buzağılar kontrol grubu buzağılara göre daha fazla kuru madde tüketmişlerdir $(P<0.01)$. Deneme boyunca, mısır ile beslenen buzağıların (1.36) yem değerlendirme etkinlikleri kontrol grubu buzağ 1 yemini tüketenlere (1.17) göre \%14 daha yüksek bulunmuştur $(P<0.01)$. Bu çalışmanın sonuçları, buzağı başlangıç yemine ilave edilen bütün mısırın buzağılarda canlı ağırlık ve günlük canlı ağırlık artışını önemli düzeyde etkilemediği, yem tüketimi ve yemden yararlanma etkinliğini ise olumlu yönde etkilediği görülmüştür.
\end{abstract}

Anahtar Kelimeler: mısır, buzağı performansı, yem tüketimi

\begin{abstract}
The aim of this study is to investigate the effects of whole corn grain supplementation to starter diet of calves on feed consumption and growth performance (from birth to 63 days old). Calves were weighed before being taken into individual compartments. Calves were randomly divided into two groups according to their initial live weight and sex. Calves were fed with colostrum for the first three days. They were fed with milk substitute food from day 3 onwards. The first group of animals were fed with calf starter feed (control group) in addition to milk replacer feed (10 females and 10 males). The second group of animals were fed with calf starter and corn (10 females and 9 males) in addition to milk replacer. Solid feeds and water were provided to calves ad-libitum throughout the trial. During the trial, the birth length and the birth weights and daily live weight gains of calves did not influenced by the gender, treatment and the interaction of treatment $\times \operatorname{sex}(P>0.05)$. Calves fed with corn consumed more dry matter than the control calves $(P<0.01)$. Overall, the feed efficiency was found to be $14 \%$ higher when calves fed with corn (1.36) than those consuming the control diet $(1.17, P<0.01)$. As a result of this study, it was observed that whole corn grain supplementation to starter diet did not significantly affect live weight and daily live weight in calves but it had a positive effect on feed consumption and feed efficiency.
\end{abstract}

Keywords: corn, calf performance, feed intake

\footnotetext{
1*Sorumlu Yazar/Corresponding Author: : Ekin Sucu, Bursa Uludağ Üniversitesi Ziraat Fakültesi Zootekni Bölümü, 16059, Nilüfer/Bursa, E-mail: ekins@uludag.edu.tr, (i) OrcID: 0000-0003-1470-2751

${ }^{1}$ Emrah Gülgün, Bursa Uludağ Üniversitesi Ziraat Fakültesi Zootekni Bölümü, 16059, Nilüfer/Bursa, E-mail: emrah.gulgun@abaliogluyem.com.tr, (D) OrcID: 0000-0001-8498-4382

${ }^{1}$ Ahmet Okumuş, Bursa Uludağ Üniversitesi Ziraat Fakültesi Zootekni Bölümü, 16059, Nilüfer/Bursa, E-mail: 051490015@ ogr.uludag.edu.tr, (iD) OrcID: 0000-0003-0356-2394

Atıf/Citation: Ekin, S., Gülgün, E., Okumuş, A. Başlangıç yemine ilave edilen mısırın siyah alaca buzağılarda yem tüketimi ve büyüme performansı üzerine etkisi. Tekirdağ Ziraat Fakültesi Dergisi, 16(3), 382-388

CBu çalışma Tekirdağ Namık Kemal Üniversitesi tarafından Creative Commons Lisansı (https://creativecommons.org/licenses/by-nc/4.0/)

kapsamında yayınlanmıştır. Tekirdağ 2019
} 


\section{Extendend Summary}

Cereal grains are the main source of starch in monogastric ruminants. The most common cereals (as a starch sources) in calf starter feeds are; corn, rice, barley, wheat, oats and sorghum. Inclusion of corn grains into the starter feed of calves; reduces the consumption of milk replacer, allows early weaning. This reduces feeding costs in calves and has a positive impact on the growth as well as anatomical development and health of rumen. Previous experiments with calves fed with additional cereal grains indicated that rumen volatile fatty acids increased (especially propionic acid and butyric acid), the physical development of rumen was stimulated. Stimulation of rumen development with volatile fatty acids promotes the growth of rumen papillae and rumen microflora. However, the number of studies investigating the effectiveness of the use of cereals in calf feeds is quite limited. Therefore, the aim of this study is to investigate the effects of whole corn on live weight, feed consumption and feed efficiency of calves.

The current experiment was conducted using a completely randomized design, 39 individually penned calves, comprising two genders (male, $n=19$ and female, $n=20$ ) were fed ad libitum from age 3 to 63 days old either with calf starter feed (Control group) in addition to milk substitute or fed with calf starter and corn (10 females and 9 males) in addition to milk substitute. Solid feeds and water were provided to calves ad-libitum throughout the trial. From the 3rd day of birth, milk replacer were started to be given to all calves $(4 \mathrm{~L}, 6 \mathrm{~L}$ and $3 \mathrm{~L}$ milk replacer twice daily for 3 to 14 days, 15 to 48 days and 49 to 63 days of age, respectively). The milk replacer powder was dissolved in warm water before given. The milk replacer powder contained $220 \mathrm{~g}$ of crude protein, $160 \mathrm{~g}$ of fat, sufficient minerals and vitamins. The corn used in the experiment contained $71 \mathrm{~g} \mathrm{~kg}^{-1}$ crude protein, $15 \mathrm{~g} \mathrm{~kg}^{-1}$ crude cellulose and $641.9 \mathrm{~g}$ starch. Solid feeds were weighed daily and given to the animals and the remaining feed was weighed down the next day. Thus, the amount of solid feed consumed daily was calculated. Live weights and lengths of calves were determined by measurements at weekly intervals. The lengths of the animals were determined using measuring tape. Feed efficiency was obtained by proportioning dry matter consumption to daily weight gain. Health records were kept regularly. The climate of the region is typically the Mediterranean climate, with a mild winter and a warm and dry summer.

At the end of the trial, the birth length and the birth weights and daily live weight gains of calves did not influenced nor by the gender, or by the treatment and the interaction between treatment $\mathrm{x}$ gender $(P>0.05)$. Dry matter consumption of corn-fed calves was found to be higher during the experiment than those of the control group calves $(P<0.01)$. The effects of sex and treatment $\mathrm{x}$ sex interaction on dry matter consumption were found to be significant $(P<0.01)$. Dry matter consumption of male calves was higher than female calves $(\mathrm{P}<0.01)$. The highest dry matter consumption was observed in corn fed male calves $(P<0.01)$. Overall, the feed efficiency was found to be $14 \%$ higher when calves fed with corn (1.36) than those consuming the control diet $(1.17, P<0.01)$. Feed efficiency of male calves was found to be $7 \%$ higher than female calves $(P<0.01)$. The highest feed efficiency was observed in male calves that fed additional corn $(1.46, P<0.01)$.

The results of this study showed that the physical form of additional corn may affect calf performance. During the liquid feed (colostrum, milk replacer) consumption (ie the first 60 days), it was observed that calves fed with a corn-containing ration performed better growth and consumed more feed. This is probably due to the fact that corn feeding contributes to the anatomical development of rumen in calves, and have a positive effect on rumen health. 
Buzağıların yaşamlarının ilk evrelerinde rasyon optimizasyonu, büyüme ve gelişmelerinde birincil öneme sahiptir. Bu durum buzağıların sindirim sisteminin yapısı ile yakından ilişkilidir (Kertz ve ark., 1998). Buzağı sindirim sisteminin fizyolojik fonksiyonlarının gelişimi ve kuru madde alımı, yemin fiziksel yapısı ile ilgilidir (Greenwood ve ark., 1997; Villalba ve Provenza, 1999; Baldwin, 2000). Buzağıların performansı sadece süt ikame yeminin özelliklerinden değil, aynı zamanda katı yem partiküllerinin boyutu ve besleme şeklinden de etkilenir (Niwińska ve Strzetelski, 2005).

Tahıl taneleri monogastrik ruminantlarda başlıca nişasta kaynağıdır. Buzağı başlangıç yemlerinde en yaygın nişasta kaynağı olarak; mısır, pirinç, arpa, buğday, yulaf ve sorgum kullanılır (Huntington, 1997). Tahıl tanelerinin buzağılara başlangıç yemine dahil edilmesi; süt ikame yeminin tüketimini azaltır ve erken sütten kesmeye olanak sağlar. Bu da buzağılarda besleme maliyetlerini düşürür, hayvanların büyümesi ve gelişimi üzerinde pozitif bir etki yaratır (Franklin ve ark., 2003). Besinlerin fermentasyonu sırasında üretilen uçucu yağ asitleri (özellikle propiyonik asit ve bütirik asit), rumenin fiziksel gelişimini uyarmaktadır (Lesmeister ve Heinrichs, 2004). Rumen gelişiminin uçucu yağ asitleri ile uyarılması, rumen papillaların ve mikrofloranın büyümesini teşvik eder (Baldwin, 1998; Lane ve ark. 2000). Önceki çalışmalar (Nocek ve ark., 1984), yem parçacıklarının yapısının ve boyutunun ruminal papillaların büyümesini etkilediğini göstermiştir. Greenwood ve ark. (1997) ince öğütülmüş yoğun yemlerin, kaba öğütülmüş yemlere kıyasla, rumen epitel hücrelerinde keratinizasyon yol açtığını bildirmiştir. Rumen mukozasında şekillenen bu tip bir keratinizasyon; ruminal papillalarının dallı ve düzensiz olmasına neden olur. Bu durumda rumende uçucu yağ asitlerinin emilimini olumsuz yönde etkilenir. Diğer taraftan, buzağıların büyük partiküllü ve farklı fiziksel formlara sahip yemleri tüketmeleri, rumenin anatomik gelişimi ve sağlı̆̆ üzerinde olumlu bir etkiye sahiptir (Lesmeister ve Heinrichs, 2004; Bach ve ark., 2007). Węglarzy ve Bilik (2008), buzağıları doğumdan 6. günden başlayarak toplam 90 gün süre ile tam yağlı süt (185 kg hayvan ${ }^{-1}, 6$ haftalıktan itibaren), mısır ve yulafla beslemişlerdir. Araştırmacılar, buzağılarda hem büyüme hızının hem de yem değerlendirme etkinliğini olumlu yönde etkilendiğini bildirmişlerdir. Lesmeister ve Heinrichs (2004), \%33’ü düzeyinde işlem görmemiş mısır içeren buzağı başlangıç yemi tüketen buzağıların ısıl işlem görmüş mısır ile beslenen hayvanlara göre daha fazla yem tükettiklerini ve canlı ağırlık performanslarının ise daha iyi olduğunu bildirmiştir.

Tahılların buzağı yemlerinde kullanımının etkinliğinin araştırıldığı çalışmaların sayısı oldukça sınırlıdır. Bu nedenle bu çalışmanın amacı, buzağı başlangıç yemine ilave edilen bütün mısırın, buzağılarda canlı ağırlık, yem tüketimi ve yem değerlendirme etkinliği üzerindeki etkilerini incelemek amacıyla yürütülmüştür.

\section{Materyal ve Yöntem}

$\mathrm{Bu}$ araştırma, Bursa Uludağ Üniversitesi'ndeki yerel Hayvan Etik Komitesi (UÜHADYEK) tarafından onaylanmıştır (onay tarihi: 17.04.2018; no:2018-06/03). Denemede 39 Siyah Alaca buzağı (20 dişi, 19 erkek) kullanılmıştır. Buzağılar doğumdan 30 dakika sonra analarından ayrılıp bireysel bölmelere taşınmışlardır. Bireysel bölmelerine altık olarak saman kullanılmıştır. Buzağıların sağlıkları düşünülerek altlık yönetimine özen gösterilmiştir. İlk 24 saatte buzağıların, 6 L kadar kolostrum içmeleri sağlanmıştır. Buzağılara 2. ve 3. günden itibaren kolostrum miktarı buzağı başına günlük 2 L olacak şekilde ayarlanmıştır. Buzağılar bireysel bölmelere alınmadan önce tartılmıştırlar ve başlangıç canlı ağırlıkları ile cinsiyetleri dikkate alınarak rasgele 2 gruba ayrılmıştır. Doğumdan sonraki 3. günden itibaren süt ikame yemi verilmeye başlanmıştır. Tüm buzağılara 3 ile 14 gün, 15 ile 48 gün ve 49 ile 63 günlük yaşta günde iki kez sırasıyla, 4 L, 6 L ve 3 L süt ikame yemi verilmiştir. Birinci grup hayvanlar süt ikame yemine ek olarak buzağı başlangıç yemi (Kontrol grubu) ile beslenmişlerdir (10 dişi ve 10 erkek). İkinci grup hayvanlar ise süt ikame yemine ek olarak buzağı başlangıç yemi ve mısır ile beslenmiştir (10 dişi ve 9 erkek). Katı yemler ve su buzağılara deneme boyunca sınırsız olarak sağlanmıştır. Süt ikame yemi verilmeden önce 1lık suda çözündürülmüştür. Süt ikame yemi $220 \mathrm{~g}$ ham protein, $160 \mathrm{~g}$ yağg, yeterli miktarda mineral ve vitamin içermiştir. Peletlenmiş buzağı başlangıç yeminin bileşenleri ve bileşimi, Çizelge 1'de verilmiştir. 
JOTAF/ Journal of Tekirdag Agricultural Faculty, 2019, 16(3)

Çizelge 1. Peletlenmiş buzağı başlangıç yeminin bileşenleri ve bileşimi

Table 1. The components and composition of the pelleted calf starter feed

\begin{tabular}{|c|c|c|c|}
\hline Hammaddeler & $\%$ & Besin Maddeleri & $\%$ \\
\hline Misir & 22.5 & Kuru madde & 85.57 \\
\hline İrmik altı unu & 20 & Ham protein & 19.7 \\
\hline Arpa & 12 & Ham selüloz & 4.78 \\
\hline Keten tohumu küspesi & 11.55 & Ham yă & 3.84 \\
\hline Misir-DDGS & 9.77 & Ham kül & 6.84 \\
\hline Misır gluten küspesi 60 & 7.04 & Nişasta & 31.81 \\
\hline Kolza tohumu küspesi 33 & 6 & $\mathrm{NDF}$ & 17.22 \\
\hline Melas & 4 & $\mathrm{ADF}$ & 7.19 \\
\hline Pirinç kepeği & 3 & $\mathrm{ADL}$ & 2.6 \\
\hline Mermer tozu & 1.6 & $\mathrm{NFC}$ & 43.71 \\
\hline Sodyum bikarbonat & 1 & & \\
\hline Tuz & 0.4 & & \\
\hline Magnezyum oksit & 0.4 & & \\
\hline Franksiyonize yağ & 0.33 & & \\
\hline Premiks & 0.2 & & \\
\hline Maya & 0.15 & & \\
\hline Toksin bağlayıcı & 0.06 & & \\
\hline
\end{tabular}

NDF, nötr deterjanda çözünmeyen lif; ADF, asit deterjanda çözünmeyen lif, ADL, asit deterjanda çözünmeyen lignin; NFC, lif olmayan polisakkaritler

Deneme kullanılan mısır $71 \mathrm{~g} \mathrm{~kg}^{-1}$ ham protein, $15 \mathrm{~g} \mathrm{~kg}^{-1}$ ham selüloz ve $641.9 \mathrm{~g}$ nişasta içermiştir. Katı yemler günlük olarak tartılarak hayvanlara verilmiş ve ertesi gün kalan yem tartılarak not edilmiştir. Böylelikle günlük tükettikleri katı yem miktarları hesaplanmıştır. Buzağıların canlı ağırlıkları ve boyları haftalık aralıklarla yapılan ölçümler ile belirlenmiştir. Hayvanların boyları ölçü şeridi kullanılarak belirlenmiştir. Yemden yararlanma etkinliği kuru madde tüketiminin günlük canlı ağırlık artışına oranlanması ile elde edilmiştir. Sağlık kayıtları düzenli olarak tutulmuştur. Bölgenin iklimi tipik olarak 1lıman bir kış ve 1lık ve kuru bir yaz olan Akdeniz iklimidir.

Tüm veriler, SPSS paket programında Genel Lineer Modelde En küçük Kareler Metodu kullanılarak analiz edilmiştir. Yem tüketimleri günlük olarak belirlendiğinden tekrar eden ölçümlü deneme desenine göre analiz edilmiştir. Canlı ağırlık, canlı ağırlık artışı ve yem değerlendirme etkinliği haftalık olarak ölçüldüğünden 2 faktörlü [cinsiyet (dişi ya da erkek) ve muamele (mısır danesi içermeyen kontrol grubu ya da mısır danesi içeren muamele grubu)] tesadüf blokları deneme desenine göre analiz edilmiştir. Gruplar arasında önem seviyelerinin belirlenmesinde Tukey testinden yararlanılmıştır.

\section{Bulgular ve Tartışma}

Buzağıların doğum boyları ve ağırlıkları üzerinde; cinsiyet, muamele ve muamele x cinsiyet interaksiyonunun etkileri önemsiz bulunmuştur (Çizelge 2,P>0.05). Benzer sonuçlar deneme sonundaki boy ve canlı ağırlıklarda da gözlenmiştir. Sonuçta, deneme boyunca buzağıların boyları, canlı ağırlıkları ve günlük canlı ağırlık artışları üzerinde cinsiyet, muamele ve muamele x cinsiyet interaksiyonunun etkileri önemsiz bulunmuştur $(P>0.05)$. Tüm buzağılar beklenen normal canlı ağırlık artış dağılımını göstermiştir. Coverdale ve ark. (2004) ile Khan ve ark. (2007) yaptıkları benzer çalışmalarda da mısır ile beslenen buzağıların vücut uzunlukları ve canlı ağırlıklarının değişmediğini tespit etmişlerdir. Diğer taraftan, Węglarzy ve Bilik (2008), 90 günlük deneme süresince bütün mısır ve yulaf tahıllarını içeren rasyonla beslenen buzağıların $\left(804 \mathrm{~g} g u ̈ n^{-1}\right)$ kontrol grubu rasyon $\left(740 \mathrm{~g}_{\text {gün }}{ }^{-1}\right)$ ile beslenenlere göre yaklaşık olarak \% 9 daha fazla canlı ağırlık kazandıklarını bildirmişlerdir. Benzer sonuçlar, Lesmeister ve Heinrichs (2004) araştırmasından da elde edilmiştir. Adı geçen araştırmada, işlem görmemiş bütün 

mısır ile beslenen buzağıların ( $469 \mathrm{~g}$ gün $\left.^{-1}\right) 1 \mathrm{~s} 1$ işlem görmüş mısır ile beslenen buzağılara (433 $\left.\mathrm{g} \mathrm{gün}^{-1}\right)$ kıyasla biraz daha fazla günlük canlı ağırlık kazandıklarını gözlemlemişlerdir.

Tüm buzağılar deneme süresince eşit miktarda süt ikame yemi (mama) tüketmiş ve süt ikame yemi (mama) tüketiminde ne gruplar arasında nede cinsiyetler arasında bir farklılık belirlenmemiştir $(P>0.05)$. Deneme boyunca bütün mısır ile beslenen buzağıların kuru madde tüketimleri kontrol grubu buzağı yemini tüketenlere göre daha yüksek tespit edilmiştir $(P<0.01)$. Kuru madde tüketimi üzerinde cinsiyet ve muamele $\mathrm{x}$ cinsiyet interaksiyonunun etkileri önemli olduğu belirlenmiştir $(P<0.01)$. Erkek buzağıların kuru madde tüketimleri dişi buzağılardan daha yüksek olmuştur $(P<0.01)$. En yüksek kuru madde tüketimi bütün mısır ile beslenen erkek buzağılarda gerçekleşmiş̧ir $(P<0.01)$. Benzer sonuçlar Lesmeister ve Heinrichs (2004) tarafından da elde edilmiştir. Tahıl danelerinin fiziksel formu, kuru madde tüketimini, rumendeki UYA'leri üretimini ve amonyak seviyesini etkilemektedir (Lesmeister ve ark., 2004). Mısır ile beslemenin kuru madde tüketimini teşvik ettiği bildirilmektedir. Bu durum; mısır ilave edilen buzağı başlangıç yemlerinin buzağılar tarafindan daha lezzetli bulunduğu ve hayvanların bu yemleri daha fazla tükettiklerini göstermektedir (Khan ve ark., 2007; Węglarzy ve Bilik, 2008). Khan ve ark. (2007) buzağı başlangıç yemi tüketiminin mısır ile beslenen buzağılarda buğday, arpa ya da yulaf ile beslenen buzağılara göre daha fazla olduğunu $(P<0.05)$ tespit etmişlerdir. Yem değerlendirme etkinliği üzerinde cinsiyet, muamele ve muamele $\mathrm{x}$ cinsiyet interaksiyonunun etkileri önemli bulunmuştur (Çizelge 2, $P<0.01$ ). Deneme boyunca mısır ile beslenen buzağıların (1.36) yem değerlendirme etkinlikleri kontrol grubu buzağ 1 yemini tüketenlere (1.17) göre \%14 düzeyinde artış göstermiştir $(P<0.01)$. Erkek buzağıların yem değerlendirme etkinlikleri dişi buzağılardan \%7 oranında daha yüksek bulunmuştur $(P<0.01)$. En yüksek yem değerlendirme etkinliği mısır ile beslenen erkek buzağılarda gerçekleşmiştir $(1.46, P<0.01)$. Węglarzy ve Bilik (2008), 90 günlük deneme süresince bütün mısır ve yulaf tahıllarını içeren rasyonla beslenen buzağıların yem değerlendirme etkinliklerini kontrol rasyonunu tüketen buzağılara göre daha yüksek bulmuşlardır. Mısır ve sorgum, diğer bazı tahıllar (buğday, arpa ve yulaf) ile karş̧laştırıldığında rumende daha yavaş fermente olurlar (Swan ve ark., 2006). Bütün mısırın diğer tahıllara nazaran daha yavaş sindirim oranına sahip olması, rumeni geçerek by-pass olan nişasta miktarını artırabileceğini düşündürmektedir. İnce bağırsakta sindirilen nişasta, sindirim son ürünlerinin (glukoz ve UYA) daha verimli kullanılması nedeniyle daha fazla enerji elde edilir. Bunlar da performansı ve yem tüketimini olumlu etkileyen unsurlardandır (Swan ve ark., 2006).

Çizelge 2. Mısır içeren buzağı başlangıç yeminin buzağı performansı üzerine etkisi

Table 2. The effect of whole corn supplemented starter feed on the calves performance

\begin{tabular}{|c|c|c|c|c|c|c|c|}
\hline Parametreler & $\begin{array}{l}\text { Boy } \\
\mathrm{cm}\end{array}$ & $\begin{array}{l}\text { Doğum } \\
\text { ağırlığı } \\
\text { kg } \\
\end{array}$ & $\begin{array}{c}\text { Canlı } \\
\text { ağırlık } \\
\text { kg } \\
\end{array}$ & $\begin{array}{c}\text { Canlı } \\
\text { ağırlık } \\
\text { artış1 } \\
\mathrm{kg} \mathrm{gün}^{-1}\end{array}$ & $\begin{array}{l}\text { Yem } \\
\text { tüketimi } \\
\mathrm{kg} \mathrm{gün}^{-1}\end{array}$ & $\begin{array}{c}\text { Kuru } \\
\text { madde } \\
\text { tüketimi } \\
\text { kg gün-1 }\end{array}$ & $\begin{array}{c}\text { Yem } \\
\text { değerlendirme } \\
\text { etkinliği }\end{array}$ \\
\hline \multicolumn{8}{|l|}{ Muamele } \\
\hline Kontrol & 85.07 & 40.00 & 64.97 & 1.29 & $1.45 \mathrm{a}$ & $1.24 \mathrm{~b}$ & $1.17 \mathrm{~b}$ \\
\hline Deneme & 86.55 & 39.35 & 64.92 & 1.34 & $1.23 \mathrm{~b}$ & $1.05 \mathrm{a}$ & $1.36 \mathrm{a}$ \\
\hline SHO & 1.34 & 0.85 & 1.85 & 0.03 & 0.13 & 0.01 & 0.07 \\
\hline $\mathrm{P}$ değeri & 0.07 & 0.68 & 0.94 & 0.91 & 0.08 & $<.001$ & $<.001$ \\
\hline \multicolumn{8}{|l|}{ Cinsiyet } \\
\hline Dişi & 86.25 & 38.75 & 63.55 & 1.28 & $1.32 \mathrm{~b}$ & $1.13 \mathrm{~b}$ & $1.22 \mathrm{~b}$ \\
\hline Erkek & 85.40 & 40.63 & 66.41 & 1.34 & $1.36 \mathrm{a}$ & $1.16 \mathrm{a}$ & $1.31 \mathrm{a}$ \\
\hline SHO & 0.56 & 0.80 & 1.84 & 0.03 & 0.01 & 0.01 & 0.07 \\
\hline $\mathrm{P}$ değeri & 0.32 & 0.13 & 0.28 & 0.60 & 0.39 & $<.001$ & $<.001$ \\
\hline
\end{tabular}

\begin{tabular}{ccccccccc}
\hline \multicolumn{2}{l}{ Muamele*Cinsiyet } & & & & & & & \\
& & & & & & & & \\
Kontrol & Dişi & 83.78 & 39.67 & 64.20 & 1.29 & $1.48 \mathrm{a}$ & $1.04 \mathrm{c}$ & $1.18 \mathrm{c}$ \\
\hline & Erkek & 86.52 & 40.30 & 65.67 & 1.35 & $1.23 \mathrm{c}$ & $1.05 \mathrm{c}$ & $1.15 \mathrm{c}$ \\
\hline Deneme & Dişi & 86.03 & 38.00 & 63.00 & 1.28 & $1.41 \mathrm{~b}$ & $1.21 \mathrm{~b}$ & $1.27 \mathrm{~b}$ \\
\hline & Erkek & 87.19 & 41.00 & 67.24 & 1.33 & $1.22 \mathrm{c}$ & $1.27 \mathrm{a}$ & $1.46 \mathrm{a}$ \\
\hline SHO & & 0.72 & 1.94 & 2.44 & 0.04 & 0.02 & 0.04 & 0.01 \\
\hline P değeri & & $<.001$ & 0.32 & 0.60 & 0.45 & 0.11 & $<.001$ & $<.001$ \\
\hline
\end{tabular}

SHO, Standart hata ortalamasi 
$\mathrm{Bu}$ çalışmanın sonuçları, ilave mısırın fiziksel formunun buzağı performansını etkileyebileceğini göstermektedir. Sıv1 yem tüketimi (kolostrum, süt ikame yemi) süresince (yani ilk 60 gün), mısır içeren bir rasyonla beslenen buzağıların daha iyi performans gösterdiği ve daha fazla yem tükettikleri gözlenmiştir. Muhtemelen bunun nedeni, mısır ile beslemenin buzağılarda rumenin anatomik gelişimine katkı sağlaması ve rumende mısırın fermantasyonu sonucunda üretilen UYA'lerinin rumen sağlığını olumlu yönde etkilemesidir. Ancak buzağıların en az 5-6 aylık yaşa kadar takip edildiği veya rumen epitel doku gelişiminin incelendiği çalışmaların yapılması gerektiği düşünülmektedir. 


\section{Kaynakça/References}

Anderson K.L., Nagaraja T.G., Morrill J.L., Avery T.B., Galitzer S.J. and Boyer J.E. 1987. Ruminal Microbial Development in Conventionally or Early-Weaned Calves. Journal of Animal Science, 64: 1215-1226.

Bach A., Giménez A., Juaristi L., Ahedo J. 2007. Effects of Physical Form of a Starter for Dairy Replacement Calves on Feed Intake and Performance. Journal of Dairy Science, 90: 3028-3033.

Baldwin R.L. 1998. Use of Isolated Ruminal Epithelial Cells in the Study of Rumen Metabolism, Journal of Nutrition, 128, 293s-296s.

Baldwin R.L. 2000. Sheep Gastrointestinal Development in Response to Different Dietary Treatments. Small Ruminant Research, 35 : $39-47$.

Baldwin R.L., Vi-McLeod K.R., Klotz, J.L. and Heitmann R.N. 2004. Rumen Development, Intestinal Growth and Hepatic Metabolism in the Pre-And Postweaning Ruminant. Journal of Dairy Science, 87: E55-E65.

Coverdale J.A., Tyler H.D., Quigley J.D., Brumm J.A. 2004. Effect of Various Levels of Forage and Form of Diet on Rumen Development and Growth in Calves. Journal of Dairy Science, 87: 2554-2562.

Franklin S.T., Amaral-Phillips D.M., Jackson J.A. and Campbell A.A. 2003. Health and Performance of Holstein Calves That Suckled or Were Hand-Fed Colostrum and Were Fed One of Three Physical Forms of Starter. Journal of Dairy Science, 86: 2145-2153.

Greenwood R.H., Morrill J.L., Titgemeyer E.C., Kennedy G.A. 1997. A New Method of Measuring Diet Abrasion and Its Effect on the Development of the Fore-stomach. Journal of Dairy Science, 80: 2534-2541.

Huntington, G.B. 1997. Starch Utilization by Ruminants: From Basics to the Bunk. Journal of Animal Science, 75: 852-867.

Kertz A.F., Barton B.A., Reutzel L.F. 1998. Relative Efficiencies of Wither Height and Body Weight Increase from Birth until First Calving in Holstein Cattle. Journal of Dairy Science, 81: 1479-1482.

Khan M.A., Lee H.J., Lee W.S., Kim H.S., Kik S., Park S.J., Ha J.K., Choi Y.J. 2007. Starch Source Evaluation in Calf Starter, I. Feed Consumption, Body Weight Gain, Structural Growth, and Blood Metabolites in Holstein Calves. Journal of Dairy Science, 90: $5259-5268$.

Lane M.A., Baldwin R.L., Jesse B.W. 2000. Sheep Rumen Metabolic Development in Response to Age and Dietary Treatments. Journal of Animal Science, 78: 1990-1996.

Lesmeister K.E., Heinrichs A.J. 2004. Effects of Corn Processing on Growth Characteristics, Rumen Development, and Rumen Parameters in Neonatal Dairy Calves. Journal of Dairy Science, 87: 3439-3450.

Niwińska B., Strzetelski J. 2005. Effects of Type of Liquid Feed and Feeding Frequency on Rumen Development and Rearing Performance of Calves. Annals of Animal Science, 5: 125-134.

Philippeau, C., Le Deschault de Monredon F. and Michalet-Doreau B. 1999. Relationship between Ruminal Starch Degradation and the Physical Characteristics of Corn Grain. Journal of Animal Science, 77: 238-243.

Swan C.G., Bowman J.G.P., Martin J.M., Giroux M.J. 2006. Increased Puroindoline Levels Slow Ruminal Digestion of Wheat (Triticum aestivum L.) Starch by Cattle. Journal of Animal Science, 84: 641-650.

Theurer C.B., Lozano O., Alio A., Delgado-Elorduy A., Sadik M., Huber J.T., Zinn R.A. 1999. Steam-Processed Corn and Sorghum Grain Flaked at Different Densities Alter Ruminal, Small-Intestinal, and Total Tract Digestibility of Starch by Steers. Journal of Animal Science, 77: 2824-2831.

Villalba J.J. and Provenza F.D. 1999. Effects of Food Structure and Nutritional Quality and Animal Nutritional State on Intake Behaviour and Food Preferences of Seep. Applied Animal Behavior Science, 63: 145-163.

Warner R.G. 1991. Nutritional Factors Affecting the Development of a Functional Ruminant. A Historical Perspective. In: Proceeding Cornell Nutrition Conference Cornell University, Ithaca, USA, 1-12.

Węglarzy K. and Bilik K. 2008. Effect of Diverse Feeding Regimes on Rearing Performance of Holstein-Friesian Red Heifer Calves. Annals of Animal Science, 2: 145-154. 